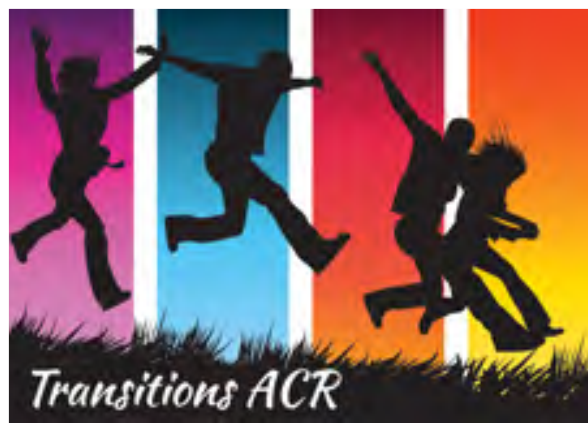

Volume 17, Issue 13

\title{
How Young Adults Can Manage Loss of Income During the COVID-19 Pandemic
}

Transitions to Adulthood Center for Research

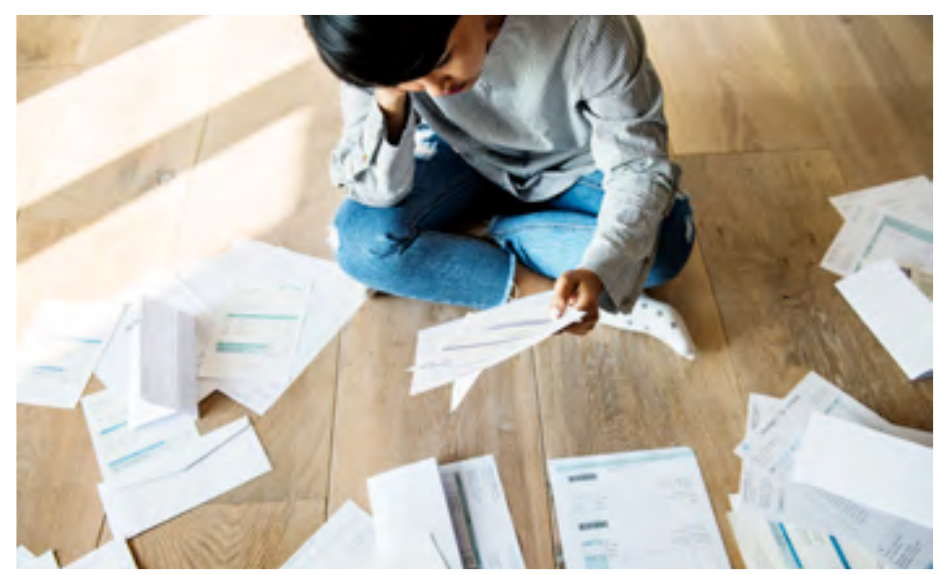

he COVID-19 pandemic has caused many people to lose income because of pay cuts, lay-offs, or furloughs. This loss of income can be very scary and may be the first time you've been on your own and out of work. It can be overwhelming to figure out how to pay your different bills (e.g., school loans, credit cards, rent, food, etc.). In order to make ends meet, you may need to use any emergency savings you've built, apply for unemployment benefits, or use your stimulus payment. This tip sheet provides some ideas and resources on how to manage if you've lost your job or are getting less pay due to the current health crisis.

\section{What Should I Do?}

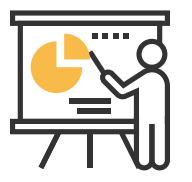

Take stock of your bills and current income (which might include unemployment benefits). You need to know what your new income is to be able to tell what you can afford to pay. Then look at your expenses and bills. Make a new budget to see what you can pay with your current income and where you are short. For example, if you lost $50 \%$ of your income, you need to cut $50 \%$ or more of your spending.

If short on funds, look at your bills and decide which ones are most important or pressing to pay (these may be food, housing, insurance, car, utilities, and medication). During this crisis, there may be options to assist you with necessary expenses that are not typically available when you lose a job.

Find creative ways to cut unnecessary expenses. This could be streaming services you may not be using or those less important to you, items you might've forgotten you've been paying for, unused gym memberships, fun shopping, unnecessary subscriptions, etc. Switch to free steaming services provided by certain television channels, some internet providers (e.g., Xfinity Stream), trial memberships (remember to cancel auto-renewals), and libraries (e.g., Hoopla app, Kanopy app). Cutting down on drinking and eating out/take-out can help you save money too.

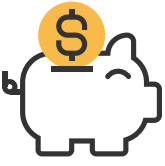

Try to reduce smoking, vaping or other tobacco related habits because this can save you a lot of money. It can be tough, but it is both beneficial to your health and your wallet. Depending on where you live, a pack-a-day smoker who quits will, on average, save $\$ 1,916$ to $\$ 4,690$ annually. https://smokefree.gov/ 
If you've lost your job, were furloughed (temporary mandatory leave of absence from work), or the company you worked for is permanently, or temporarily shut down because of COVID-19, you may qualify for weekly unemployment payments from the state where you worked. It's encouraged that you file for unemployment as soon as possible.

\section{Check out for information:}

CareerOneStop Unemployment:

https://www.careeronestop.org/WorkerReEmployment/UnemploymentBenefits/unemploymentbenefits.aspx

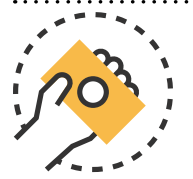

If you haven't gotten your federal stimulus check yet go to https://www.irs.gov/ coronavirus/economic-impact-payments on the IRS website.

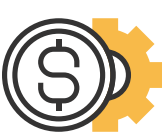

Contact the different companies to whom you owe money and talk to them about your situation to find out what your options are. Many companies are willing to work with people having trouble making payments. Check the company's website to see if it has any messages about COVID-19.

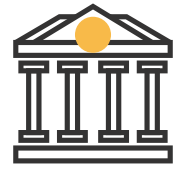

State and local governments have made it easier for residents to get food assistance during the coronavirus crisis. If you are having trouble paying for food, try applying for the Supplemental Nutrition Assistance Program, or SNAP ("food stamps") in the state you live in: https://www.fns.usda.gov/snap/state-directory.

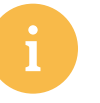

Check with your state, city, or town to see if they have any additional food benefits or services that may apply to your situation. Some town residents have setup "neighborly" programs via social media (Facebook and NextDoor). Clubhouses, drop-in centers, and other mental health organizations may be able to assist in providing or locating free and/or reduced cost food.

If you are receiving benefits from a government-funded assistance program (e.g., SNAP, WIC, TANF, SSI, etc.), you are likely able to get food from a local food bank or pantry. Visit websites like Feeding America, Foodpantries.org, or PantryNet.org to find one. You'll need to show proof you are enrolled in an eligible program or proof of income, which may include earnings from employment, unemployment or social security benefits.

Many utility companies (i.e., electricity, gas, etc.) will work with you to make sure you do not lose service during this time. Several states, cities, and towns have declared a "state of emergency," which means it now may be illegal for your utility provider to turn off your service right now. If you can't pay your utility bill, contact the company to find out what can be done to defer or lower payments for now. 
If you can't pay your mortgage, contact the mortgage lender (the company you send monthly mortgage payments to) and discuss options. It may take time to get through to them, given high call volumes and possibly reduced staff, so be prepared for longer wait times than usual. Also, check your local government's websites to see if they have anything about mortgage relief options. Once you can pay again, contact the mortgage lender as soon possible.

If you can't pay your rent, talk to your landlord to let them know you've lost your income due to the pandemic and can't pay. Per the CARES Act, if you are renting from an owner who has a federally backed mortgage, you cannot be evicted for nonpayment of rent for 120 days beginning on March 27, 2020. If the property you rent isn't covered by the CARES Act, many states have stopped all evictions and foreclosures due to the pandemic, so check your state's website for information.

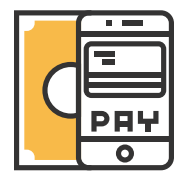

If your student loans are held by the federal government, your loan payments have been automatically postponed with no interest. You do not need to do anything. You might want to check with your lender though, to see when your next payment is due. If you can afford to pay them, doing so is a good idea, as the payment will go directly toward the principal.

For other kinds of student loans (such as a federal student loan held by a commercial lender or the institution you attend, or a private student loan held by a bank, credit union, school, or other private entity) contact your student loan servicer to find out more about your options. They may be willing to work out a flexible option with you.

\section{(2)} iil

If you don't have enough money to pay your credit card bills, call the credit card companies as soon as possible and explain your situation.

Act Fast If You Can't Pay Your Credit Cards: https://files.consumerfinance.gov/f/documents/cfpb act fast credit cards final web_020816.pdf

ii Many car loans have deferred peoples' car payments for a short time. Contact your lender to see if they have any options available to help you lower or defer your monthly payments until you return to work.

Keep documentation of every call that you make (e.g., date/time), who you talked to and all decisions that were made. Always ask for an email or text to follow-up with the agreement so you have everything in writing.

Make sure you understand what it means to temporarily postpone or reduce payments or use other hardship programs. Delaying payments may lead to accrued interest and extended repayment timing. Communication with the companies to whom you owe money is key. 


\section{Online Resources}

Act Fast If You Can't Pay Your Credit Cards: https://files.consumerfinance.gov/f/documents/cfpb act fast_credit_cards_final_web_020816.pdf

CareerOneStop Unemployment: https://www.careeronestop.org/WorkerReEmployment/ UnemploymentBenefits/unemployment-benefits.aspx

Consumer Financial Protection Bureau: Cutting Expenses: https://files.consumerfinance.gov/f/ documents/cfpb your-money-your-goals cutting-expenses tool 2018-11.pdf

Consumer Financial Protection Bureau: Guide to Coronavirus Mortgage Relief Options: https://www. consumerfinance.gov/about-us/blog/guide-coronavirus-mortgage-relief-options/

Consumer Financial Protection Bureau: What You Need to Know about Student Loans and the Coronavirus Pandemic: https://www.consumerfinance.gov/about-us/blog/what-you-need-to-knowabout-student-loans-and-coronavirus-pandemic/

Consumer Financial Protection Bureau: Your Money, Your Goals: https://www.consumerfinance.gov/ practitioner-resources/your-money-your-goals/

Find Local Food Bank: https://www.feedingamerica.org/find-your-local-foodbank

How to Qualify for Food Banks: https://www.sapling.com/7605063/qualify-food-banks

IRS Non-Filers: Enter Payment Info Here: https://www.irs.gov/coronavirus/non-filers-enter-paymentinfo-here

Low-Income Home Energy Assistance Program (LIHEAP): https://liheapch.acf.hhs.gov/

Retooling Your Budget For COVID-19? 5 Smart Steps To Take Now: https://www.forbes.com/sites/ advisor/2020/03/27/retooling-your-budget-for-covid-19-5-smart-steps-to-take-now/\#29b92c23580e

Tenant protection during the novel coronavirus outbreak: https://blog.augrented.com/renting-duringthe-novel-coronavirus-outbreak/

U.S. Department of Agriculture: https://www.fns.usda.gov/news-item/usda-021520

U.S. Department of Labor: https://www.dol.gov/coronavirus/unemployment-insurance

What to Do If You're Struggling with Monthly Payments During the Coronavirus: https://www. thebalance.com/how-to-manage-monthly-payments-during-the-coronavirus-4842564

Worried about making your auto loan payments? Your lender may have options that can help: https:// www.consumerfinance.gov/about-us/blog/worried-about-making-your-auto-loan-payments-your-lendermay-have-options-to-help/

Recommended Citation: Logan, D. (2020). How Young Adults Can Manage Loss of Income During the COVID-19 Pandemic. Worcester, MA: University of Massachusetts Medical School, Department of Psychiatry, Implementation Science and Practice Advances Research Center (iSPARC), Transitions to Adulthood Center for Research.

The contents of this tip sheet were supported in part under grants with funding from the National Institute on Disability, Independent Living, and Rehabilitation Research, (NIDILRR), United States Departments of Health and Human Services (NIDILRR grant number 90RTEM0005, The Learning and Working Transitions RRTC). NIDILRR is a Center within the Administration for Community Living (ACL), Department of Health and Human Services (HHS). The contents of this tip sheet do not necessarily represent the policy of NIDILRR, ACL, or HHS and you should not assume endorsement by the Federal Government. 